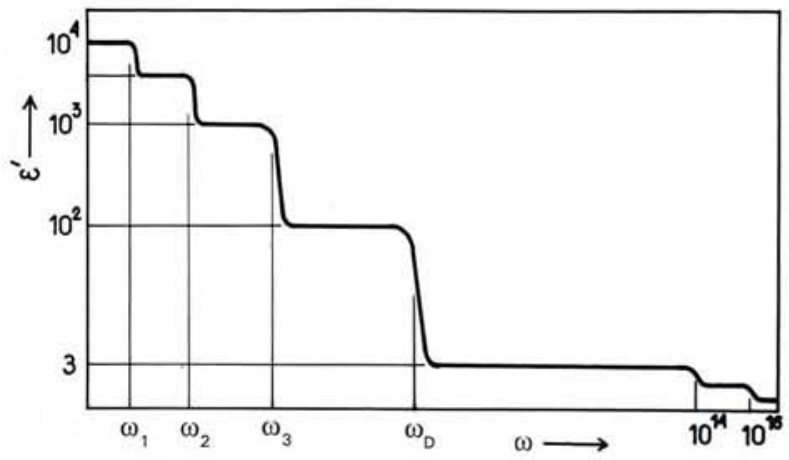

Fig. 7 - Frequency dependence of the real part of the dielectric permittivity of ice. "Steps" at $\omega_{1}, \omega_{2}, \omega_{3}$ and $\omega_{D}$ correspond to the motion of charge carriers of four different types.

cates the depth of the superionic surface layer. Fig. 8 illustrates the ice surface structure.

\section{Mechanical Properties of Ice}

In a number of natural phenomena, in which ice is subjected to alternating mechanical stresses - drift of temporary ice, compression of sea ice, etc., electromagnetic radiation is emitted. This has already found practical application, for example, in air reconnaissance of the regions of compression of sea ice for navigation and for forecasting the drift of temporary ice. However, until recently the nature of this radiation was enigmatic. Ice possessing a structure with a "statistical" (from the disordering of $\mathrm{H}_{2} \mathrm{O}$ molecules) symmetry centre cannot be piezoelectric and emit RF waves when vibrated.

In our experiments, ice subjected to non-uniform elastic stresses demonstrated a pseudo piezo effect. It turned out that proton charge carriers, deforming the ice lattice around themselves, produced a noticeable dilatation. In other words, ions $\mathrm{H}_{3} \mathrm{O}^{+}$and $\mathrm{OH}^{-}, \mathrm{L}$ and $\mathrm{D}$-defects occupy volumes different from those of $\mathrm{H}_{2} \mathrm{O}$ molecules. In the presence of elastic-stress gradients, the charge carriers move along them like an air bubble along a pressure gradient in water. Hence, in non-uniform fields of elastic stress, electric currents arise that can quite easily be measured, and they suffice to explain the RF emission of ice. In practice, ice becomes piezoelectric not only in the presence of temperature

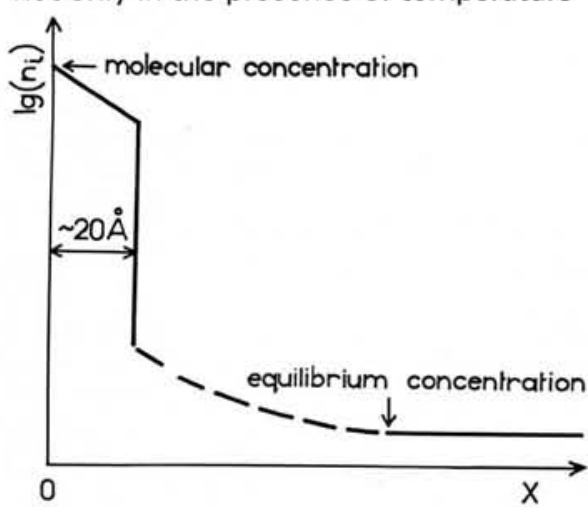

Fig. 8 - Distribution of charge carrier concentration near the ice surface. gradients but also impurity concentrations [9] which are common in natural conditions.

Dislocation currents, observed by Petrenko and Whitworth during plastic deformation of ice can now be attributed to the charge-carrier dilatation in ice. Charge carriers can be trapped by fields of non-uniform stresses existing around dislocations, the dislocations become electrically charged and by their motion generate electric currents. Carrier concentrations near such dislocation cores can exceed by several orders the mean values in the bulk. These must be taken into account in the description of the dislocation motion conditions, as shown by Petrenko and Ryzhkin.

Finally, we have solved rather accurately the problem of the reorientation of $\mathrm{H}_{2} \mathrm{O}$ molecules in ice under the action of elastic stresses, so creating a theory of inelastic relaxation of ice. One important outcome from this work has been a theory of propagation of sonic waves.

This short review of some recent results presents only a small part of the intensive studies in ice physics now being carried out across the world. We can expect this fascinating field of solid state physics to provide us with many important fundamental results which will find practical applications in future.

\section{REFERENCES}

[1] Jaccard C., Phys. Cond. Mat. 3 (1964) 99. [2] Hubbman M., Z. Phys. B 32 (1979) 127.

[3] Chesnakov V.A., Petrenko V.F., Ryzhkin I.A. and Zaretskii A.V., J. de Physique, C1 99 (1987).

[4] Petrenko V.F., Whitworth R.W. and Glen J.W., Phil. Mag. B 47 (1984) 259.

[5] Petrenko V.F., "Electrical Properties of Ice", VII International Symposium on the Physics and Chemistry of Ice, 1-5 September 1986, Grenoble.

[6] Petrenko V.F. and Ryzhkin I.A., Phys. Stat. Sol. (b) 121 (1984) 421.

[7] Petrenko V.F. and Maeno N., J. de Physique, C1 48 (1987) 115.

[8] Ryzhkin I.A., Sol. Stat. Com. 51 (1985) 57.

[9] Evtushenko A.A., Maeno N., Petrenko V.F. and Ryzhkin I.A., J. de Physique, C1 109 (1987).

\section{Hewlett-Packard Europhysics Prize 1989}

\section{Call for Nominations}

The Selection Committee for the Hewlett-Packard Europhysics Prize invites nominations for the 1989 award. The prize is given for an outstanding contribution to condensed matter physics within the previous five years, with the potential for leading to advances in the fields of electronic, electrical or materials engineering. Nominations may be submitted by EPS members as individuals or as representatives of a Division or Section.

During this decade the HewlettPackard Prize has been awarded to the following:

1980 - O. Krogh Andersen and

A.R. Miedema

1982 - K. von Klitzing

1983 - I. Silvera

1984 - G. Binnig and H. Rohrer

1985 - J. Als-Nielsen and M. Pepper

1986 - F. Mezei

1987 - I. Yanson

1988 - J.G. Bednorz and K.A. Müller

In order to maintain this extremely high standard, it is necessary that the Committee receive proposals which represent the breadth and strength of European condensed matter physics. It is also important that the submitted nominations be complete, and it is our experience that this is not always the case. They should comprise at least:

- a detailed motivation for the award,

including a clear definition of the work and its significance;

- a brief curriculum vitae of the nominee;

- a list of relevant publications.

It is also extremely helpful if we receive letters of support from authorities in the field, in which the importance of the work is evaluated. These can with advantage also be sollicited from nonEuropean physicists.

EPS members who know of a qualified candidate for the Hewlett-Packard Prize are urged to submit a complete nomination to the Selection Committee, to arrive before the end of August. All information will be treated as strictly confidential.

Nominations should be addressed to:

Selection Committee,

H-P Europhysics Prize

EPS, POB 69

$\mathrm{CH}-1213$ Petit-Lancy 2

\section{A.R. Mackintosh}

Chairman,

Hewlett-Packard Prize Selection Committee 